\title{
Theoretical evaluation of substituted polycyclic aromatic hydrocarbons as emerging pollutant phototoxins
}

\author{
K. Rowberg, N. Nataraj, W. Saroian \& L. Kang \\ Department of Chemistry and Physics, Purdue University Calumet, \\ Hammond, IN, USA
}

\begin{abstract}
Phototoxicity potential was predicted for 88 substituted PAHs. The geometry of all PAHs was optimized and the molecular orbital energies were calculated using AM1 Hamiltonian. The highest occupied molecular orbital energy $\left(\mathrm{E}_{\mathrm{HOMO}}\right)$ and the lowest unoccupied molecular orbital energy $\left(\mathrm{E}_{\mathrm{LUMO}}\right)$ were used to calculate the energy gap $\left(\mathrm{E}_{\mathrm{HOMO}}-\mathrm{E}_{\mathrm{LUMO}}\right)$. The energy gap was used to predict phototoxicity for chloro-, bromo-, nitro- and methyl-substituted PAHs. Of the 88 compounds in the study, only nitro substituents on carbazole were predicted to induce phototoxicity of the nonphototoxic parent.
\end{abstract}

Keywords: polycyclic aromatic hydrocarbons, PAH, phototoxicity, HOMOLUMO gap, emerging pollutants.

\section{Introduction}

Polycyclic aromatic hydrocarbons (PAHs) are planar, nonpolar, semi-volatile chemical compounds that are composed of two or more fused aromatic rings. PAHs originate from point sources (e.g. oil spills, industrial processes [1] and fossil fuel combustion) or non-point source pollutants (e.g. atmospheric deposition, road runoff, forest fires, and volcanoes). Rain may move PAHs deposited on the soil to the groundwater. Although PAHs have low aqueous solubility, they readily adsorb on sediment of the groundwater. Phase equilibria between sediment and water and mass transfer controls the release of PAHs from nonaqueous phase liquids or sediment into the aqueous phase. Although PAHs are formed primarily as by-products of carbonaceous fuel consumption, PAHs 
are found in air, deposited on land, dissolved in water, adsorbed on sediments and even in the fatty tissue of animals.

PAHs can undergo chemical and photochemical transformation to substituted PAHs. The rate of transformation varies by PAH component, reagent, matrix (air, water, or soil) and availability of light. Although 16 unsubstituted PAHs are regularly monitored by USEPA, substituted PAHs are not well characterized or monitored regularly.

Emerging chemicals are synthetic or naturally compounds that are not commonly monitored in the environment but have potential to cause adverse ecological or human health effects. Other emerging chemicals such as carbon nanotubes (NT) and nanoribbons (NR) have promise as pharmaceutical and electronic materials [2], yet the safety of these materials is not well characterized. Studies of intratracheal exposure of rat lung to NT reported multifocal granuloma lesions [3]. No known studies of phototoxicity of NT or NR and their derivatives were found by these authors.

Reactions of PAHs with reactive species in the environment may give rise to emerging pollutants. Air pollutants react with PAHs to form substituted PAHs. One source of nitro-PAHs is diesel exhaust, of which 1-nitropyrene is a major component [4]. Reactions of PAHs in an aqueous environment occur. For example, PAHs adsorbed to humic material react with hypochlorite to form chlorinated PAHs [5]. These emerging pollutants may not be acutely toxic, may cause tumor growth [6] or induce phototoxicity [7].

Computational methods have been used to correlate molecular orbital energy to carcinogenicity [8] and phototoxicity [9] in PAHs. Specifically, a parabolic relationship was seen for PAH triplet state energy and photoxicity [9]. Mekenyan et al. [11] examined the phototoxicity data and correlated it with HOMO-LUMO gap energy $\left(\mathrm{E}_{\mathrm{HOMO}}-\mathrm{E}_{\mathrm{LUMO}}\right)$. The phototoxic $\mathrm{PAHs}$ were within a window of gap energy ranging of 6.8 to $7.6 \mathrm{eV}$. They interpreted the parabolic relationship as a superposition of the PAH's capacity to attain the excited state by absorbing radiation and chemical stability.

In a study of substituted-PAH phototoxicity [12], Veith et al. calculated the HOMO-LUMO energy gap for a test group of six PAHs and their derivatives (chloro, nitro, hydroxyl and alkyl groups - both saturated and unsaturated). Although alkyl substituents increased the HOMO-LUMO energy gap relative to the unsubstituted parent $\mathrm{PAH}$, the increase was not significant. The largest decrease of the HOMO-LUMO energy gap caused by substitution was for diethenyl fluorene. Large decreases of the HOMO-LUMO energy gap were also found for nitro- and chloro-substituted PAHs. These substituents - ethenyl, nitro and chloro - may delocalize into aromatic rings. Their alkyl and hydroxyl substituents did not significantly affect the HOMO-LUMO energy gap in the compounds studied. The study concluded that phototoxicity is likely only if the parent PAH is phototoxic, and for the six parent PAH compounds in the study, no substituent-induced phototoxicity was predicted.

In a recent study [13], de Lima Ribeiro and Ferreira calculated the HOMOLUMO energies for 14 PAHs using semi-empirical molecular orbital calculations using the method AM1. The energies and the phototoxicity were 
used as the training data to determine the Gaussian type relationship between these molecular descriptors and phototoxicity. Their model suggested an acute phototoxicity window in the energy gap range 6.5-7.9 eV. The HOMO-LUMO gap was determined for 52 unsubstituted PAHs and compared to their established window of toxicity. Phototoxicity was predicted for 41 of the PAHs, including pentaphene, benzo[b]chrysene and dibenz[a.j]anthracene by the model.

This paper reports the HOMO-LUMO energy gaps calculated for 88 PAHs (seven parent PAHs). The effect of substituents on the parent $\mathrm{PAH}$ is the difference between the parent PAH energy gap and the substituted PAH energy gap. The HOMO-LUMO energy gap was used in predicting phototoxicity.

\section{Method}

The purpose of this study was to determine the effect of substituents on the ground state HOMO-LUMO energy gap of seven parent PAHs. The PAHs chosen were anthracene, benzo[a]pyrene, benzo[b]fluoranthene, benz[a]anthracene, acridine, carbazole and chrysene (see Figures 1-7). The substituents included nitro, chloro, bromo, and methyl, all chosen for their chemical availability as reactants in the environment.

Nanoribbons (NR) as emerging chemicals were also included in this study. NR fragments included were $2 \times 4,2 \times 5$, and $4 \times 6$ fused rings (see Figures 8-10).<smiles>c1ccc2cc3ccccc3cc2c1</smiles>

Figure 1: Anthracene.<smiles>C1=Cc2cc(cc3ccccc23)-c2ccccc21</smiles>

Figure 3: $\quad$ Benzo[b]fluoranthene.

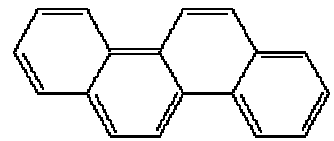

Figure 5: Chrysene.<smiles>c1ccc2c(c1)cc1ccc3cccc4ccc2c1c34</smiles>

Figure 2: Benzo[a]pyrene.

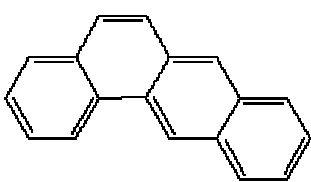

Figure 4: Benz[a]anthracene.<smiles>C1=c2cc3ccccc3nc2=CCC1</smiles>

Figure 6: Acridine. 


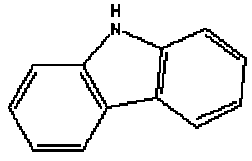

Figure 7: Carbazole.

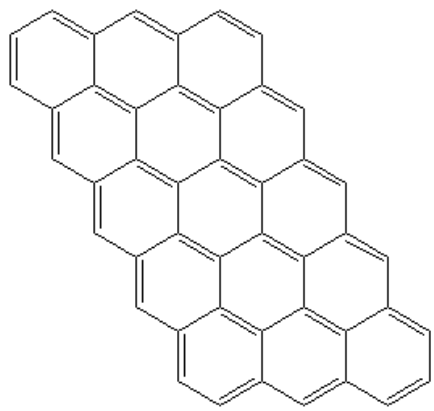

Figure 9: $\quad 3 \times 5$ Nanoribbon.

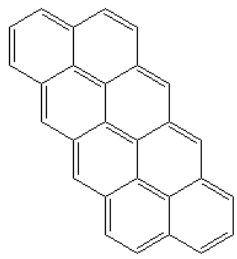

Figure 8: $2 \times 4$ Nanoribbon.

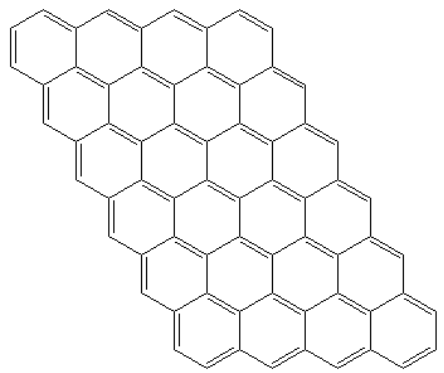

Figure 10: $4 \times 6$ Nanoribbon.

The molecules were drawn and optimized using the drawing program in Hyperchem 7.1 [13] using the MM+ database. The molecular energies were minimized and the molecular orbital energies were determined using a semiempirical calculations using AM1 [14] method. The differences in the HOMO and LUMO energies wer tabulated in Tables 1-8.

\section{Results and discussion}

The calculated HOMO-LUMO energy gaps for the 88 parent and substituted PAHs are presented in Tables 1-7. The HOMO-LUMO gaps for the 3 NR fragments are in Table 8 . The substituents selected represent those substituents with potential to decrease the HOMO-LUMO energy gap and also those found as reactive species in the environment. $\mathrm{PAH}$ substitution patterns were chosen to replicate substitution patterns found in internet searches of the reaction products of the parent PAH. The parent PAH HOMO-LUMO gaps reported here vary slightly from those reported in the literature $[11,12]$, however, the variation is minimal. The HOMO-LUMO gap energies of parent PAH and of the substituted PAH were used to predict changes in phototoxicity.

All parent PAHs studied, except carbazole, were in de Lima Ribeiro and Ferreira's window of phototoxicity [13]. Except for a negligible increase in gap energy of 1-methylbenz[a]anthracene, substituents uniformly decrease the HOMO-LUMO energy gap as compared to the unsubstituted PAH. Nitro substituents on carbazole decrease the energy gap sufficiently to shift the position of the nonphototoxic parent PAH within the window of phototoxicity. 
The energy gaps for 1-nitro, 3-nitro and 4-nitrocarbazole are 7.6, 7.7 and 7.8 eV, respectively. The nitro substituents shift the energy gap of the parent unsubstituted carbazole $(8.2 \mathrm{eV})$ into the phototoxic window of de Lima Ribeiro and Ferreira [13] (6.5-7.9 eV). No substituent was deemed effective to shift the position of the phototoxic parent PAH outside the window of toxicity.

Table 1: $\quad$ HOMO-LUMO Gap.

Table 2: $\quad$ HOMO-LUMO Gap.

\begin{tabular}{|ll|ll|}
\hline Molecule & Gap & Molecule & Gap \\
\hline Anthracene & 7.284 & 7.217 \\
$1-\mathrm{Cl}$ & 7.247 & Benzo[a]pyrene & 6.811 \\
$2-\mathrm{Cl}$ & 7.216 & $1-\mathrm{Cl}$ & 6.768 \\
$1-\mathrm{Br}$ & 7.245 & $2-\mathrm{Cl}$ & 6.811 \\
$2-\mathrm{Br}$ & 7.019 & $10-\mathrm{Cl}$ & 6.767 \\
$\mathrm{NO}_{2}$ & 7.120 & $1-\mathrm{Cl}$ & 6.773 \\
$\mathrm{NO}_{2}$ & & $2-\mathrm{NO}_{2}$ & 6.599 \\
& & $3-\mathrm{NO}_{2}$ & 6.767 \\
$10-\mathrm{NO}_{2}$ & 6.655 \\
\hline
\end{tabular}

Table 3: $\quad$ HOMO-LUMO Gap.

\begin{tabular}{|cc|}
\hline Molecule & Gap \\
\hline Benzo[b]fluoranthene & 7.602 \\
$9-\mathrm{Cl}$ & 7.527 \\
$10-\mathrm{Cl}$ & 7.573 \\
$11-\mathrm{Cl}$ & 7.529 \\
$12-\mathrm{Cl}$ & 7.492 \\
$9-\mathrm{NO}_{2}$ & 7.398 \\
$10-\mathrm{NO}_{2}$ & 7.374 \\
$11-\mathrm{NO}_{2}$ & 7.487 \\
$12-\mathrm{NO}_{2}$ & 7.319 \\
\hline
\end{tabular}

The largest decreases for nitro substituted carbazole energy gap was 0.58 $\mathrm{eV}$ for 1-nitrocarbazole, $0.52 \mathrm{eV}$ for 3-nitrocarbazole and $0.42 \mathrm{eV}$ for 4nitrocarbazole. Substitution of nitro at the 2-position resulted in only $0.13 \mathrm{eV}$ decrease. Similarly, 4- nitro substituent on chrysene reduced the HOMOLUMO gap by $0.46 \mathrm{eV}$, whereas other nitro substituents on chrysene decreased the gap by 0.24 to $0.34 \mathrm{eV}$, except for the 5-nitro substituent which decreased the energy gap by only 0.15 . The small decrease in energy gap for the 5-nitro substituent can be explained by the orientation of the substituent to the aromatic ring. Whereas all other nitro substituents were coplanar with the aromatic ring, steric hindrance at the 5-position of carbazole forced the nitro substituent out of plane. This in turn will reduce the delocalization of the nitro substituent with the ring. 
Table 4: $\quad$ HOMO-LUMO Gap.

Table 5: $\quad$ HOMO-LUMO Gap.

\begin{tabular}{|c|c|c|c|}
\hline Molecule & Gap & Molecule & Gap \\
\hline Benz[a]anthracene & 7.392 & Chrysene & 7.697 \\
\hline $1-\mathrm{Cl}$ & 7.388 & $1-\mathrm{Cl}$ & 7.624 \\
\hline $2-\mathrm{Cl}$ & 7.343 & $2-\mathrm{Cl}$ & 7.671 \\
\hline $3-\mathrm{Cl}$ & 7.370 & $3-\mathrm{Cl}$ & 7.653 \\
\hline 7-Cl & 7.252 & $4-\mathrm{Cl}$ & 7.585 \\
\hline $9-\mathrm{Cl}$ & 7.364 & $5-\mathrm{Cl}$ & 7.613 \\
\hline $10-\mathrm{Cl}$ & 7.349 & $6-\mathrm{Cl}$ & 7.572 \\
\hline $12-\mathrm{Cl}$ & 7.267 & $1-\mathrm{NO}_{2}$ & 7.352 \\
\hline $1-\mathrm{NO}_{2}$ & 7.153 & $2-\mathrm{NO}_{2}$ & 7.458 \\
\hline $2-\mathrm{NO}_{2}$ & 7.159 & $3-\mathrm{NO}_{2}$ & 7.445 \\
\hline $3-\mathrm{NO}_{2}$ & 7.214 & $4-\mathrm{NO}_{2}$ & 7.234 \\
\hline $7-\mathrm{NO}_{2}$ & 7.067 & $5-\mathrm{NO}_{2}$ & 7.542 \\
\hline $9-\mathrm{NO}_{2}$ & 7.205 & $6-\mathrm{NO}_{2}$ & 7.386 \\
\hline $10-\mathrm{NO}_{2}$ & 7.199 & $1-\mathrm{CH}_{3}$ & 7.647 \\
\hline $12-\mathrm{NO}_{2}$ & 7.165 & $2-\mathrm{CH}_{3}$ & 7.676 \\
\hline $1-\mathrm{CH}_{3}$ & 7.415 & $3-\mathrm{CH}_{3}$ & 7.649 \\
\hline $2-\mathrm{CH}_{3}$ & 7.359 & $4-\mathrm{CH}_{3}$ & 7.583 \\
\hline $3-\mathrm{CH}_{3}$ & 7.375 & $5-\mathrm{CH}_{3}$ & 7.601 \\
\hline 7- $\mathrm{CH}_{3}$ & 7.285 & $6-\mathrm{CH}_{3}$ & 7.583 \\
\hline 9- $\mathrm{CH}_{3}$ & 7.364 & & \\
\hline $10-\mathrm{CH}_{3}$ & 7.350 & & \\
\hline $12-\mathrm{CH}_{3}$ & 7.301 & & \\
\hline
\end{tabular}

The similarity is gap shift for nitro substituents on carbazole and chrysene compares favorably to that observed by Veith et al. [12] who noted that gap energy decrease due to nitro substitution decreased with increasing number of rings in the parent $\mathrm{PAH}$. In this study, carbazole, with three rings, and chrysene, with four rings, have gap energy decreases due to a nitro substituent of up to 0.58 and $0.46 \mathrm{eV}$, respectively.

Both carbazole and acridine contain a nitrogen heteroatom in the parent PAH which could facilitate delocalization of the electrons of the PAH nitrogen to the nitro substituent. For acridine, the largest gap decrease is for the 9-nitro substituent $(0.43 \mathrm{eV})$ in which the nitro is "para" to the aromatic ring nitrogen. Even though acridine is a three-ring PAH, its largest energy gap decrease due to the presence of a substituent is slightly less than that for chrysene with four rings ( 0.43 compared to $0.46 \mathrm{eV})$.

In contrast to the large gap decreases mentioned above, the decrease in the HOMO-LUMO energy gap for 2-nitrocarbazole is only $0.13 \mathrm{eV}$ similar to the value of $0.16 \mathrm{eV}$ for 2-nitroacridine. The importance of substituent placement on gap energy has not been elucidated, but inductive and resonance effects will be investigated in future studies. 
Table 6: HOMO-LUMO Gap.

Table 7: HOMO-LUMO Gap.

\begin{tabular}{|ll|}
\hline Molecule & Gap \\
\hline Acridine & 7.532 \\
$1-\mathrm{Cl}$ & 7.452 \\
$2-\mathrm{Cl}$ & 7.478 \\
$3-\mathrm{Cl}$ & 7.493 \\
$4-\mathrm{Cl}$ & 7.419 \\
$9-\mathrm{Cl}$ & 7.366 \\
$1-\mathrm{NO}_{2}$ & 7.298 \\
$2-\mathrm{NO}_{2}$ & 7.375 \\
$3-\mathrm{NO}_{2}$ & 7.383 \\
$4-\mathrm{NO}_{2}$ & 7.338 \\
$9-\mathrm{NO}_{2}$ & 7.102 \\
$1-\mathrm{CH}_{3}$ & 7.443 \\
$2-\mathrm{CH}_{3}$ & 7.476 \\
$3-\mathrm{CH}_{3}$ & 7.490 \\
$4-\mathrm{CH}_{3}$ & 7.453 \\
$9-\mathrm{CH}_{3}$ & 7.423 \\
\hline
\end{tabular}

\begin{tabular}{|ll|}
\hline Molecule & Gap \\
\hline Carbazole & 8.231 \\
$1-\mathrm{Cl}$ & 8.140 \\
$2-\mathrm{Cl}$ & 8.134 \\
$3-\mathrm{Cl}$ & 8.176 \\
$4-\mathrm{Cl}$ & 8.122 \\
$1-\mathrm{NO}_{2}$ & 7.648 \\
$2-\mathrm{NO}_{2}$ & 8.098 \\
$3-\mathrm{NO}_{2}$ & 7.712 \\
$4-\mathrm{NO}_{2}$ & 7.809 \\
$1-\mathrm{CH}_{3}$ & 8.161 \\
$2-\mathrm{CH}_{3}$ & 8.153 \\
$3-\mathrm{CH}_{3}$ & 8.208 \\
$4-\mathrm{CH}_{3}$ & 8.163 \\
\hline
\end{tabular}

Table 8: $\quad$ HOMO-LUMO Gap for Carbon Nanoribbons.

\begin{tabular}{|ll|}
\hline Molecule & Gap \\
\hline NR $2 \times 4$ & 5.505 \\
NR $3 \times 5$ & 4.079 \\
NR $4 \times 6$ & 2.806 \\
\hline
\end{tabular}

Chloro substituents decreased the HOMO-LUMO energy gap minimally and bromo substituents even less. The largest decrease for a chloro substituent was for 9-chloroacridine, for which the gap decreased by only $0.17 \mathrm{eV}$. Although this demonstrates the small effect of a chloro substituent on the energy gap it highlights the importance of the 9-position on acridine. The 9-position provided the largest decrease in energy gap of the five substituent positions analyzed.

The largest parent PAH in the study, benzo[a]pyrene, had the smallest HOMO-LUMO gap $(6.8 \mathrm{eV})$ and the effect of substituents decreased the gap only slightly. Again, this is in agreement with previous results in which the effect of a single substituent on the energy gap decreased as the size of the parent PAH increased [11]. From this present study, increasing number of rings of parent PAH correlated with decreasing gap energy, and substituent effect on gap energy was influenced more by the presence of a heteroatom on the PAH and position of the substituent.

The size of parent was extended by considering the emerging chemicals, nanoribbons. To estimate phototoxicity, the HOMO-LUMO gap for $2 \times 4,3 \times 5$, and $4 \times 6$ fragments were determined (see Table 8 ). The gaps were well below the phototoxic windows in the literature $[11,12]$. A low energy gap has been 
suggested to represent both unstable chemical structures and absorption of low energy light. The prediction, therefore, is that nanoribbons will not be phototoxic due to either unstable chemical structure or low energy light absorption or both.

\section{Conclusion}

Phototoxicity potential was predicted for 88 substituted PAHs based on their HOMO-LUMO energy gap. In agreement with previous studies, nitro substituents decreased the energy gap more than chloro, bromo and methyl substituents. Although acute phototoxicity to aquatic species is inferred for nitrocarbazoles, whether this is ecologically relevant is uncertain. While it may be argued that aquatic bioavailability is low for these hydrophobic compounds, lipid rich larvae may readily adsorb the compounds when available. Mitigating factors, such as the effect of humic materials, may decrease the effect of light on phototoxic compounds. Hypothetically, a clear lake having little humic material may experience PAH loading from road runoff after development and personal watercraft use, and, therefore, may experience aquatic phototoxicity from PAHs. Predictions of phototoxicity are not to be taken as an alarm for imminent danger, but as factor to consider in environmental impact assessment.

\section{Acknowledgements}

Le Kang and W. Saroian thank Purdue University Calumet Undergraduate Research Office for a grant to purchase software for the project. K. Rowberg thanks Purdue University Research Foundation for an international travel grant to present this paper.

\section{References}

[1] Petkewich, R., Toxic by-products of nanotubes. Chemical \& Engineering News, 85(35), p. 12, Aug. 27, 2007.

[2] Halford, B., Graphene ribbons. Chemical and Engineering News, 86(4), p. 15, Jan. 28, 2008.

[3] Lam, C., James, J.T., McCluskey, R. \& Hunter, R.L., Toxicity of singlewall carbon nanotubes in the lungs of mice exposed by intratracheal instillation (Chapter 8). Nanotechnology and the Environment. Applications and Implications, eds. Karn, B., Masciangioli, T., Zhang, W., Colvin, V. \& Alivisatos, P., ACS Symposium Series 890: Washington DC, pp. 60-66, 2005.

[4] Warheit, D.B., Laurence, B.R., Reed, K.L., Roach, D.H., Reynolds, G.A.M. \& Webb, T.R., Lung toxicity bioassay study in rats with single-wall carbon nanotubes (Chapter 9). Nanotechnology and the Environment. Applications and Implications, eds. Karn, B., Masciangioli, T., Zhang, W., Colvin, V. \& Alivisatos, P., ACS Symposium Series 890: Washington DC, pp. 67-90, 2005. 
[5] Toriba, A. Hayakawa, K., Simpson, C.D., Kitaoka, H., Dills, R.L., Mizukami, S., Tanabe, K., Takeuchi, N., Ueno, M., Kameda, T. \& Tang, N., Identification and Quantification of 1-Nitropyrene Metabolites in Human Urine as a Proposed Biomarker for Exposure to Diesel Exhaust. Chemical Research and Toxicology, 20, p. 999-1007, 2007.

[6] Georgi, A., Reichl, A., Trommler, U. \& Kopinke, R.-D., Influence of sorption to dissolved humic substances on transformation reactions of hydrophobic organic compounds in water. I. Chlorination of PAHs. Environmental Science and Technology, 41, pp. 7003-7009, 2007.

[7] Neff, J.M., Polycyclic Aromatic Hydrocarbons in the Aquatic Environment. Applied Science Publishers: London, 1979.

[8] Oris, J.T., Giesy, J.P., Allred, P.M., Grant, D.F. \& Landrum, P.F., Photoinduced toxicity of anthracene in aquatic organisms: an environmental perspective. The Biosphere: Problems and Solutions, Veziroglu, T. ed., Elsevier Science Publishers: Amsterdam, pp. 639-658 1984.

[9] Morgan, D., Warshawsky, D. \& Atkinson, T., The relationship between carcinogenic activities of polycyclic aromatic hydrocarbons and their singlet, triplet, and singlet-triplet splitting energies and phosphorescence lifetimes. Photochemistry \& Photobiology, 25, pp. 31-38, 1977.

[10] Newsted, J.L. \& Giesy, J.P., Predictive models for photoinduced acute toxicity of polycyclic aromatic hydrocarbons to Daphnia magna, Strauss (Cladocera, Crustacea). Environmental Toxicology \& Chemistry, 6, pp. 445-461, 1987.

[11] Mekenyan, O.G., Ankley, G.T., Vieth, G.D. \& Call, D.J., QSARs for photoinduced toxicity: I. acute lethality of PAHs to Daphnia magna. Chemosphere, 28, pp. 567-582, 1994.

[12] Vieth, G.D., Mekenyan, O.G., Ankley, G.T. \& Call, D.J., A QSAR analysis of substituent effects on the photoinduced acute toxicity of PAHs. Chemosphere, 30, pp. 2129-2142, 1995.

[13] de Lima Ribeiro, F.A. \& Ferreira, M.M.C., QSAR model of the phototoxicity of polycyclic aromatic hydrocarbons. Journal of Molecular Structure: THEOCHEM, 719(1-3), pp. 191-200, 2005.

[14] Hyperchem release 7.52, Hypercube, Inc., 1115 N.W. $4^{\text {th }}$ Street, Gainesville FL 32601, USA.

[15] Dewar, M.J.S., Zoebisch, E.G., Healy, E.F. \& Stewart, J.J.P., Development and use of quantum mechanical molecular models. 76. AM1: a new general purpose quantum mechanical molecular model, Journal of the American Chemical Society, 107, pp. 3902-3909, 1985. 